Ensino, Saúde e Ambiente - V5 (2), pp. 2-12, ago. 2012

\title{
JORNAL DA CIÊNCIA COMO ATIVIDADE INTERDISCIPLINAR EXTRACLASSE: DETABES E REFLEXÕES SOBRE A CIÊNCIA NA COMUNIDADE ESCOLAR DE ENSINO MÉDIO \\ SCIENCE JOURNAL AS EXTRA-CURRICULAR INTERDISCIPLINARY ACTIVITY: DISCUSSIONS AND REFLECTIONS ABOUT SCIENCE ON THE COMMUNITY SCHOOL OF SECONDARY EDUCATION
}

\author{
Joelma Goldner Krüger ${ }^{1}$, Sidnei Quezada Meireles Leite ${ }^{2}$ \\ ${ }^{1}$ Professora de Química da Rede Estadual do Espírito Santo. Especialista em EJA e PROEJA. Mestranda \\ do Programa de Pós-graduação em Educação em Ciências e Matemática do Instituto Federal do Espírito \\ Santo. E-mail: joelmagoldner@gmail.com \\ ${ }^{2}$ Professor de Educação em Ciências, D.Sc., Programa de Pós-graduação em Educação em Ciências e \\ Matemática, Campus Vitória, Instituto Federal do Espírito Santo. E-mail: squezada@ifes.edu.br
}

\section{RESUMO}

O Jornal Escolar da Ciência (JEC) é uma atividade interdisciplinar extracurricular de caráter cultural e educativo promovido pelo Programa Estadual de Iniciação Científica Júnior da FAPES e CNPq. O objetivo deste trabalho foi analisar o processo de construção do jornal da ciência na escola publica de ensino médio, promovendo debates e reflexões sobre as questões relativas à ciência, tecnologia e ambiente, na comunidade escolar em uma região a margem da sociedade, além de se constituir um espaço de aprendizagem para os alunos de iniciação científica do projeto escolar. A equipe deste projeto foi formada por cinco alunos do ensino médio, um aluno de licenciatura, professores de ciências e pesquisadores. Cada número do JEC é composto por um editorial, uma pesquisa desenvolvida no Espírito Santo, uma pesquisa em nível de Brasil/Mundo, um personagem da história da ciência e um acontecimento local. Acreditamos que este projeto contribuir com a alfabetização científica, rompendo paradigmas herdados da visão fragmentada do conhecimento presente nas salas de aula.

Palavras-chave: alfabetização científica, jornal escolar, interdisciplinaridade, iniciação científica júnior, CTSA

\begin{abstract}
The Science Journal in School is an extracurricular interdisciplinary activity, cultural and educational, promoted by the Program of Junior Scientific Initiation of Research Support Foundation of the Espírito Santo State and CNPq/Brazil. This research aimed to analyze the process of building the science journal in the public high school, promoting discussion and reflection on issues relating to science, technology and environment, in school community in a region to the margins of society, constituting a learning space for undergraduate students of the school project. The project team consisted of five high school students, an undergraduate student, science teachers and researchers. Each edition of the journal is comprised of an editorial, a research developed in Espírito Santo State, a research level of Brazil/World, a fact in the history of science and a local event. It seems this project contributes to scientific literacy, breaking paradigms of this fragmented view of knowledge in classrooms.
\end{abstract}

Key words: scientific literacy, school journal, interdisciplinary, junior scientific initiation, STSE 


\section{INTRODUÇÃO}

Em 2011, a Fundação de Amparo à Pesquisa do Estado do Espírito Santo criou o Programa Estadual de Iniciação Científica Júnior com apoio do CNPq. Este programa é uma política publica que visa, entre outros objetivos, aproximar as instituições de pesquisa das escolas públicas do estado do Espírito Santo e promover mudanças nas práticas pedagógicas realizadas na sala de aula da educação básica pública, especialmente as situadas em regiões à margem da sociedade. Cada projeto financiado apresenta um pequeno recurso de equipamento e custeio, bolsas de iniciação científica para alunos do ensino médio e bolsa de iniciação científica para alunos de cursos de graduação.

A partir de uma parceria entre o Campus Vitória do Instituto Federal do Espírito Santo (IFES) e uma Escola Estadual, buscamos reunir alunos do ensino médio, professores de ciências (Física, Química e Biologia) e pesquisadores, para debater e refletir questões da ciência, tecnologia e ambiente, a partir da divulgação periódica do Jornal da Ciência produzido mensalmente por essa equipe de trabalho. O Jornal da Ciência é uma atividade interdisciplinar extracurricular de caráter cultural e educativo, composto por um editorial, uma pesquisa desenvolvida no Espírito Santo, uma pesquisa em nível de Brasil/Mundo, um personagem da história da ciência e um acontecimento local. Essa proposta está respaldada pela possibilidade de promover alfabetização científica na comunidade escolar. Segundo Chassot alfabetização científica é:

[...] como uma linguagem para a descrição e compreensão do mundo natural [...] Defende-se que a alfabetização científica - um analfabeto científico é aquele que não sabe ler a linguagem em que está escrita a natureza - possa ser responsável não apenas pela facilitação do entendimento do mundo, mas por ajudar a transformá-lo em algo melhor. A alfabetização científica é vista também como possibilidade para fazer inclusão social, sendo óbice para isso o presenteísmo (vinculação exclusiva ao presente, sem enraizamento com o passado e sem perspectivas com o futuro) e o cientificismo (crença exagerada no poder da Ciência e/ou atribuição à mesma de fazeres apenas benéfico). O dogmatismo, marcado pelo positivismo, é apresentado como uma das marcas para uma não alfabetização científica (CHASSOT, 2003, p. 90).

A dinâmica social contemporânea está fortemente condicionada pelo desenvolvimento científico-tecnológico. Partindo do pressuposto de que a sociedade, como um todo, possui o direito de participar em definições que envolvem seu destino, considera-se fundamental a democratização de processos decisórios que envolvem temas vinculados 
à Ciência-Tecnologia (CT). Por exemplo, Auler (1998) enfocou o surgimento histórico do Movimento CTSA no campo educacional, a tradução dos seus objetivos em novas configurações curriculares, os problemas e as perspectivas encontradas, bem como os desafios que se colocam para o ensino de Ciências (formação de professores) no contexto educacional brasileiro. Entre esses problemas e desafios situados como possíveis questões de investigação, destacamos: formação disciplinar dos professores incompatível com a perspectiva interdisciplinar presente no movimento CTSA; compreensão dos professores sobre as interações entre ciência, tecnologia e sociedade; não contemplação do enfoque CTSA nos exames de seleção; formas e modalidades de implementação; produção de material didático-pedagógico; e redefinição de conteúdos programáticos (Auler e Bazzo, 2001).

No campo da educação científica, o Movimento CTSA encontra-se em ressonância com as ideias educacionais de Paulo Freire, por apoiar o ensino das ciências mais humanista, tendo em vista a conscientização social de que a ciência e a tecnologia são elementos da cultura, compreendendo a sala de aula como espaço educativo de construção de cidadania (Freire, 2002; Auler e Delizoicov, 2006).

O objetivo deste trabalho foi analisar o processo de construção do jornal da ciência na escola publica de ensino médio, promovendo debates e reflexões sobre as questões relativas à ciência, tecnologia e ambiente, na comunidade escolar em uma região a margem da sociedade, além de se constituir um espaço de aprendizagem para os alunos de iniciação científica do projeto escolar.

\section{METODOLOGIA DA PESQUISA}

\section{A) O Estudo}

A pesquisa foi desenvolvida nos moldes de um estudo de caso, de natureza qualitativa e de caráter exploratório, conforme Marcone e Lakatos (2009). Procuramos apresentar uma reflexão e análise a cerca da alfabetização científica promovida no processo de construção de jornal escolar da ciência. Para organização desse projeto na escola, foram necessárias reuniões de equipes com os professores de ciências, seleção dos alunos de iniciação científica mediadas por prova e entrevistas e realização de oficinas formativas de jornal da ciência.

\section{B) Local da Pesquisa}


A presente investigação foi realizada na Escola Estadual de Ensino Fundamental e Médio (EEEFM) Marinete de Souza Lira, situada na Rua Vitória Régia, S/N, Bairro Feu Rosa, Município de Serra, Espírito Santo, CEP: 29164-450.

\section{C) Sujeitos}

Os sujeitos dessa pesquisa foram os alunos de IC Jr do ensino médio, o aluno de IC, professores colaboradores da área de ciências (Física, Química e Biologia) participantes do projeto "Jornal Escolar da Ciência". Para garantir a integridade dos sujeitos envolvidos, resolvemos preservar a identidade, não sendo divulgada nenhuma informação que possibilite a identificação dos mesmos. As informações fornecidas serão utilizadas somente para realização da pesquisa.

\section{D) Coleta e Análise dos Dados}

Os dados coletados com base em observações, análise de documentos oficiais, leituras de artigos e livros da área de Ensino de Ciências e Matemática e aplicação de entrevistas coletivas com os sujeitos envolvidos para levantamento das percepções. Foram analisados as percepções dos alunos de IC ao longo das reuniões de equipe, buscando identificar indícios de alfabetização científica, promovida pelas atividades à luz do movimento CTSA. Além disso, também analisamos os aspectos as abordagens educacionais, a presença da interdisciplinaridade e a complexidade na forma da transdisciplinaridade. Essas categorias foram escolhidas para dar clareza na organização e análise dos conteúdos tendo como referência principal, Bardin (2004).

\section{O JORNAL DA CIÊNCIA COMO PRÁXIS INOVADORA}

O projeto "Jornal Escolar da Ciência" é desenvolvido numa escola de um bairro carente da região metropolitana da Grande Vitória, no Estado do Espírito Santo. Por apresentar muitos conflitos em decorrência dos problemas de drogas e violência, é considerada uma região à margem da inclusão social e educacional. A comunidade é necessitada de atendimentos em todos os níveis: educação, saúde, segurança e trabalho. As famílias trabalhadoras necessitam que as crianças e adolescentes exerça alguma atividade para a complementação da renda familiar, sendo este, um dos motivos de evasão escolar e repetência, conforme relato de alguns professores.

Com a realização do projeto "Jornal Escolar da Ciência", há a promoção de debates sobre as questões da ciência, da tecnológica, do ambiente e sobre algumas questões de ordem cidadã, referentes aos problemas do bairro onde vivem. A construção 
do jornal segue um modelo pedagógico progressista, à luz do Movimento Ciência, Tecnologia, Sociedade e Ambiente (CTSA). A partir dos questionamentos dos alunos, percebemos que, de alguma forma, promove-se alfabetização científica. De alguma forma, há certa emancipação política e sociocultural de jovens e adultos participantes diretamente do projeto.

Jornal é um meio de comunicação impresso, geralmente um produto derivado do conjunto de atividades denominado jornalismo. As características principais de um jornal são: o uso de "papel de imprensa" - mais barato e de menor qualidade que os utilizados por outros materiais impressos; a linguagem própria - dentro daquilo que se entende por linguagem jornalística; e é um meio de comunicação de massas - um bem cultural que é consumido pelas massas. Os jornais têm conteúdo genérico, pois publicam notícias e opiniões que abrangem os mais diversos interesses sociais. No entanto, há também jornais com conteúdo especializado em economia, negócios ou desporto, entre outros. A periodicidade mais comum dos jornais é a diária, mas existem também aqueles com periodicidade semanal, quinzenal e mensal. No caso da presente proposta, busca-se criar um Jornal da Ciência na Escola com periodicidade mensal. Para Bonini (2011), a prática do jornal escolar vem ao encontro das propostas dos Parâmetros Curriculares Nacionais, promovendo a conexão de saberes e melhoria do processo de ensino-aprendizagem da língua portuguesa no contexto brasileiro.

Para Miranda (2006), a articulação da construção do jornal com as rotinas escolares se constitui em um processo de Educomunicação. A Educomunicação busca facilitar a produção e difusão da informação, promover a interatividade dos processos de ensino-aprendizagem e fornecer os referenciais teóricos e metodológicos necessários à análise da produção cultural para efeito de uma adequada formação para o relacionamento com o sistema massivo de meios de informação (Soares, 2000). Para tanto, as práticas educomunicativas privilegiam os conceitos de comunicação dialógica; de ética de responsabilidade social para os produtores culturais; de recepção ativa e criativa por parte das audiências; de política de uso dos recursos da informação de acordo com os interesses dos polos envolvidos no processo de comunicação e, consequentemente, da ampliação dos espaços de expressão (Soares, 2000).

Para Morin, o termo epistemologia da complexidade, ou do "Complexus [do latim] - o que é tecido junto" (MORIN, 1997, p. 44), integra os modos de pensar em oposição à forma linear, reducionista do pensamento. O Projeto "Jornal Escolar da Ciência" quer vivenciar este novo paradigma promovendo a alfabetização científica 
numa perspectiva de transdiciplinaridade. As artes levam-nos à dimensão estética da existência e - conforme o adágio que diz que a natureza imita a obra de arte - elas nos ensinam a ver o mundo esteticamente. Trata-se, enfim, de demonstrar que, em toda grande obra, de literatura, de cinema, de poesia, de música, de pintura, de escultura, há um pensamento profundo sobre a condição humana (MORIN, 2010, p. 45). Os filmes, os romances e os poemas são, para Morin, meios didáticos importantes para a uma educação que incorpore a epistemologia da complexidade, porque permite a percepção do outro com sua instabilidade e identidade própria e, ao mesmo tempo, a percepção do universal em realidades que se nos expressam diversos acontecimentos sociais e históricos.

\section{O JORNAL DA CIÊNCIA NA PERSPECTIVA DA COMPLEXIDADE E DO MOVIMENTO CTSA}

Duas perspectivas marcaram a construção do jornal da ciência na escola pública, sendo que a primeira delas foi a perspectiva da complexidade e a segunda foi tomar a filosofia do movimento CTSA, com seus eixos cidadania, contextualidade, interdisciplinaridade e transdisciplinaridade, como temas norteadores das atividades desenvolvidas.

No campo educacional a complexidade aparece como "transdisciplinaridade". Uma educação que questiona os modelos reducionistas e fragmentados, a divisão em disciplinas compartimentalizadas em áreas, em departamentos que não contribuem para a emancipação das pessoas. Uma educação transdisciplinar busca o diálogo entre os diversos tipos de conhecimento, une as diferenças no processo de construção do conhecimento e pressupõe a utilização de diversas linguagens. Entre as linguagens Morin destaca as artes como forma de facilitar a aprendizagem do aluno na vivência deste novo paradigma.

As artes levam-nos à dimensão estética da existência e - conforme o adágio que diz que a natureza imita a obra de arte - elas nos ensinam a ver o mundo esteticamente. Trata-se, enfim, de demonstrar que, em toda grande obra, de literatura, de cinema, de poesia, de música, de pintura, de escultura, há um pensamento profundo sobre a condição humana (MORIN, 2006, p. 45).

As artes levam-nos à dimensão estética da existência e - conforme o adágio que diz que a natureza imita a obra de arte - elas nos ensinam a ver o mundo esteticamente. Trata-se, enfim, de demonstrar que, em toda grande obra, de literatura, de cinema, de poesia, de música, de pintura, de escultura, há um pensamento profundo sobre a 
condição humana (MORIN, 2010, p. 45). Os filmes, os romances, o poema são para Morin meios didáticos importantes para a uma educação que incorpora a epistemologia da complexidade porque permite a percepção do outro com sua instabilidade e identidade própria e a percepção ao mesmo tempo da universalidade, realidades que se nos expressam diversos acontecimentos sociais e históricos.

Já na perspectiva do Movimento CTSA, uma análise crítica da ciência e das questões ambientais foi explicitamente comentada pelos alunos no decorrer das primeiras reuniões e das oficinas do jornal da ciência. Logo no início das oficinas, discutiu-se com os alunos os aspectos históricos e o contexto em que a Rio + 20 está inserida. Essa discussão foi desenvolvida à luz do movimento CTSA, como é citado por Auler e Bazzo (2001) que defende a idéia de que o movimento visa promover o interesse dos estudantes em relacionar a ciência com as aplicações tecnológicas e os fenômenos da vida cotidiana; abordar o estudo daqueles fatos e aplicações científicas que tenham uma maior relevância social; abordar as implicações sociais e éticas relacionadas ao uso da ciência e da tecnologia e adquirir uma compreensão da natureza da ciência e do trabalho científico. Além da concepção sobre o movimento, discutiu-se com os alunos e mantiveram-se presente ao longo das oficinas os princípios do movimento: cidadania; contextualização; interdisciplinaridade e transdisciplinaridade.

O desafio que se colocou no desenvolvimento deste componente nas duas perspectivas comentadas era vivenciar com os alunos uma inovação em relação ao ensino de ciências, e levar os alunos a perceberem que a ciência é interrelacionada e que sofre influências culturais, políticas e sócio-econômicas. Ao lado deste desafio estava a consciência da importância de começar um trabalho com os alunos que estavam chegando, acolhendo-os bem, promovendo a integração da turma, e apresentando o curso de Licenciatura em Química, escolhido pelos mesmos, como algo prazeroso.

\section{A CONSTRUÇÃO DO JORNAL DA CIÊNCIA}

O desenvolvimento do Projeto do Jornal da Ciência teve três etapas. Vale citar que este trabalho se debruçou a analisar a etapa I deste projeto de extensão. Na Etapa I, houve o Treinamento/Formação dos alunos de ensino médio. Consistiu no período de atividades dos bolsistas no qual estão envolvidos com reuniões, oficinas de orientação e palestras sobre o tema abordado, além de realização do estudo dirigido e treinamento da metodologia. Vale citar que na Etapa I foi constituído um grupo de trabalho formado por cinco alunos de Ensino Médio (bolsistas de Iniciação Científica Júnior), professores 
das mais diversas áreas, um aluno de iniciação científica da Licenciatura em Química e pesquisadores.

$\mathrm{Na}$ primeira Oficina de Contextualização do Jornal, houve uma pequena atividade de integração do grupo e foi feita uma apresentação geral do projeto de extensão. Na tentativa de demonstrar as possibilidades do jornal escolar, alguns temas foram debatidos tais como o vazamento de água de uma rede local do bairro, a dengue, a obtenção de água potável, a importância de um museu da cultura e da ciência, a importância do Instituto de Pesquisa da Economia para o Estado do Espírito Santo, a agropecuária no Estado do Espírito Santo, entre outros. Para nortear as discussões, foram utilizados jornais de circulação regional e nacional como fonte de pesquisa. Alguns alunos deram seu depoimento a cerca da importância desse projeto em suas vidas, destacando-se a oportunidade de se aprender mais sobre a ciência e novas culturas, visando fomentar opiniões futuras. Como forma de marketing, os bolsistas sugeriram uma comunicação de curiosidades em forma de manchete, para chamar atenção dos potenciais leitores.

Na Etapa II acontece o desenvolvimento do jornal propriamente dito, quando o respectivo responsável por cada coluna constrói o seu texto e há o processo de melhoramento por meio das reuniões com o monitor e a equipe de professores. A Etapa III acontece a apresentação de um pôster em um Seminário de Avaliação dos Projetos de PIBIC Jr, promovidos pela FAPES.

Com a constituição da equipe de trabalho, foi possível estabelecer uma organização para o jornal escolar, cujos temas tratados foram: (a) editorial, "um fato na ciência no Espírito Santo", "um fato na ciência no Brasil ou no mundo", "um fato na história da ciência" e "aconteceu!". Esse grupo de trabalho é coordenado por professor da área de ciências com apoio dos gestores da escola. Mensalmente, um editorial é um texto de apresentação do jornal da ciência construído por um dos integrantes.

A coluna da "Ciência no Espírito Santo" é construída por meio de uma prévia investigação de um grupo de pesquisa de umas das instituições de pesquisa do estado do Espírito Santo. Esse processo de busca é enriquecedor porque promove descobertas e uma ampliação da visão de mundo. Os alunos podem lançar mão de uma entrevista e de fotografias, quando é possível e viável.

As Colunas da "Ciência no Brasil/América Latina/Mundo" e "História da Ciência" são construídas por meio de uma pesquisa na internet a partir de algum tema identificado nos jornais ou revistas de divulgação científica. Já a Coluna “Aconteceu”, 
está é construída com base em algum acontecimento local ou regional com implicações socioambientais. Nesse caso, busca-se levantar os fatos daquele mês por meio de entrevistas e reportagens realizadas no jornal local e da TV.

Durante a Oficina de Produção do Jornal percebemos que os alunos se motivaram com os temas apresentados. Discutirmos a percepção dos alunos a partir de fotografias, a partir de imagens e pequenos textos. Também foram discutidas algumas questões com base na forma do jornal. Finalmente, foram aplicadas algumas dinâmicas com base em temas pré-estabelecidos: a obtenção da água potável, as pesquisas realizadas pelo Incaper e a realização do Rio+20. Os alunos receberam pequenos textos sobre esses assuntos e tiveram que produzir um pequeno resumo. $\mathrm{O}$ objetivo destas dinâmicas foi desenvolver opinião crítica sobre os temas apresentados. Esse fato corrobora as propostas do movimento CTSA, promovendo uma visão crítica sobre a ciência e a tecnologia, participando mais ativamente das questões de cidadania (Morais, 2006).

\section{Coordenador: O que é ciência?}

Alunos: Tudo o que estuda a nossa vida. O cotidiano!

Aluna A: A busca pelas respostas, a filosofia.

Aluna I: Estudo de todas as coisas.

Coordenador: Então é a busca pela compreensão dos fatos da vida?

Alunos: Sim!

Aluna J: A busca pela compreensão de coisas incompreensíveis.

Aluna J: Ciência é tudo!

Percebe-se na fala da aluna J "A busca pela compreensão de coisas incompreensíveis", no qual ela mesma chega à seguinte conclusão "Ciência é tudo!". A aluna está correta! O Jornal Escolar contemplará todas as ciências, ou seja, todas as grandes áreas de estudo, segundo o Conselho Nacional de Desenvolvimento Científico e Tecnológico (CNPq). Depois solicitou aos alunos bolsistas para pensarem na concepção do jornal (o que vai tratar/como vai ser construído) e depois a forma, o tipo do jornal. Foram apresentadas as áreas escolhidas de um estudo realizado pelos professores do curso de CTS (Ciência, Tecnologia e Sociedade) da rede pública do Estado do Espírito Santo, e por fim sendo sugerido a utilização desses temas como norteadores para o Jornal Escolar. Os temas são: Agricultura; Água Potável; Biocombustível; Saúde e Alimentação; Energia; Vícios, Violência e Valorização Da Vida; Lixo; Mármore e Granito; e Petróleo; e Biotecnologia e Transgênicos. 
Coordenador: Será que a ciência é igual à de antes?

Aluna I: As coisas mudaram.

Coordenador: Poderia ser um estudo sobre determinado assunto!

Alunos: Sim.

Por tratar de assuntos relacionados ao desenvolvimento do Estado do Espírito Santo, acredita-se que esse trabalho possa servir como catalisador para a definição do futuro dos jovens, buscando indicar possíveis caminhos a serem percorridos na sua vida pessoal e profissional. Talvez, ao desenvolver esse projeto, a escola passe a se localizar na rota do conhecimento científico nas várias áreas do conhecimento, levando ao jovem a sonhar com um bom curso técnico em uma boa escola ou com sua formação acadêmica em nível de graduação em uma Universidade/Instituto. Os temas tratados no Jornal Escolar servirão como geradores de discussão em sala de aula, propiciando a racionalização e a apropriação dos conteúdos de forma lúdica e significativa para alunos e professores. Já em na outra parte da Oficina de Produção de Jornal a monitora do Projeto abarcou com os alunos bolsistas sobre a redação de um Jornal, no qual ela destacou as seguintes partes: origem do Jornal Escolar; vantagens do Jornal Escolar; objetivos; tipos de Jornais que podem ser utilizados no projeto; redação; matérias; diagramação; e material visual.

Durantes as reuniões contempladas na Etapa I (Treinamento/Formação) também houve, por meio do coordenador geral, oficinas para o desenvolvimento da percepção dos alunos e da capacidade de relatar algum fato de uma forma simples e atraente para os futuros leitores do Jornal Escolar. Além disso, começou-se a desenhar, juntamente com os alunos, o formato do Jornal Escolar, encerrando desta forma a Etapa I do projeto de extensão.

\section{CONSIDERAÇÕES FINAIS}

Busca-se introduzir, por meio da construção de um jornal, uma prática pedagógica lúdica na Escola para servir como eixo de articulação entre as práticas realizadas na sala de aula e o cotidiano dos alunos e professores. Sob esse aspecto, percebemos que a prática do Jornal Escolar da Ciência se constituiu em uma prática educacional inovadora.

Conforme Edgar Morin, os filmes, os romances, o poema são para meios didáticos importantes para a uma educação que incorpora a epistemologia da complexidade. A prática do Jornal da Ciência na Escola promoveu um processo 
epistemológico que incorpora a complexidade. Esse fato permite ampliar a visão de mundo dos alunos de ensino médio, sobretudo aqueles que vivem em região à margem da inclusão social.

Com relação ao movimento CTSA, buscou-se promover o interesse dos estudantes em relacionar a ciência com as aplicações tecnológicas e os fenômenos da vida cotidiana. Abordou-se as implicações sociais e éticas relacionadas ao uso da ciência e da tecnologia, promovendo uma visão crítica sobre a ciência e a tecnologia, participando mais ativamente das questões de cidadania

Entendemos que houve uma contribuição para a formação de cidadania, a partir da formulação de uma opinião critica e do desenvolvimento do indivíduo para participar ativamente na sociedade democrática, na busca de solução de problemas que envolvam aspectos tecnológicos, sociais, econômicos e políticos.

\section{REFERÊNCIAS}

AULER, Décio. Movimento Ciência-Tecnologia-Sociedade (CTS): modalidades, problemas e perspectivas em sua Implementação no ensino de física. In: Encontro de Pesquisa em Ensino de Física, 6, Livro de Resumos, Florianópolis, 1998.

AULER, Décio.; BAZZO, Walter Antonio. Reflexões para a implementação do movimento CTS no contexto educacional brasileiro. Ciência e Educação, v. 7, n. 1, p. $1-13,2001$.

AULER, Décio; DELIZOICOV, Demétrio; Educação CTS: articulação entre pressupostos do educador Paulo Freire e referenciais ligados ao movimento CTS, Las relaciones CTS em la educación, ISBN 84.689.8925-8, 2006.

BARDIN, Laurence. Análise de conteúdo, 3a . Edição, Lisboa: Edições 70, 2004.

BONINI, Adair; Jornal escolar: gêneros e letramento midiático no ensino-aprendizagem de linguagem. RBLA, Belo Horizonte, v. 11, n. 1, p. 149-175, 2011.

CHASSOT, Attico. Alfabetização científica: uma possibilidade para a inclusão social. Revista Brasileira de Educação. n.22, p. 90 - 100, Jan./Apr, 2003.

FREIRE, Paulo. Pedagogia da autonomia. 24 ed. São Paulo: Paz e Terra, 2002.

MARCONI, Marina de Andrade.; LAKATOS, Eva Maria; Metodologia do Trabalho Científico, $7^{\mathrm{a}}$. Edição Revista e Ampliada, São Paulo:Editora Atlas, 2009.

MIRANDA, Amanda Souza; O Jornal Escolar e a Educação Problematizadora: vislumbrando uma aproximação. UNIrevista - Vol. 1, n. 3 , jul, 2006.

MORAIS, Roberto José da Cunha. Ensino de CTS e educação científica: práticas pedagógicas adotadas na oitava série do ensino fundamental. 2006. 30p. Monografia (Especialização em Ensino de Ciências) - Centro Federal de Educação Tecnológica de Química de Nilópolis, Rio de Janeiro, 2006.

MORIN,Edgar. Meus demônios. Rio de Janeiro: Bertrand Brasil, 1997.

MORIN, Edgar. A Cabeça Bem-Feita. Rio de Janeiro: Bertrand Brasil, 2010.

SOARES, Ismar de Oliveira. Educomunicação: as perspectivas do reconhecimento de um novo campo de intervenção social: o caso dos estados unidos. Disponível em: $<\mathrm{http}$ //portal.uninove.br/marketing/cope/pdfs_revistas/eccos/eccos_v2n2/eccosv2n2_is mardeoliveira.pdf> Acesso em: 27, nov ,2011. 